Estudios sobre el Mensaje Periodístico

ISSN-e: $1988-2696$

http://dx.doi.org/10.5209/ESMP.55617

\title{
La Aurora de Chile y los orígenes del periodismo chileno (1812-1813)
}

\author{
Eduardo Santa Cruz Achurra ${ }^{1}$
}

Recibido: 3 de febrero de 2016 / Aceptado: 29 de abril de 2016

Resumen. El objetivo del texto es dar cuenta de la labor periodística de la Aurora de Chile, en el contexto de los inicios del proceso de la independencia nacional. Dicha labor se inscribió en el desarrollo del modelo de prensa doctrinaria, que fuera predominante en América Latina a lo largo del siglo XIX. Esta investigación analizó todos los números publicados por el periódico, develando su estructura formal, los temas escogidos, las fuentes de origen de sus informaciones y los criterios explícitos de sus decisiones periodísticas, complementado con el estudio de libros y artículos referidos al tema. El texto muestra la estrategia periodística del medio, en su propósito de ayudar a la formación de un espacio público proclive a la independencia total del país.

Palabras clave: Historia de la prensa chilena; siglo XIX; modelo de prensa doctrinaria; Aurora de Chile.

\section{[en] Aurora de Chile and the early Chilean journalism (1812-1813)}

\begin{abstract}
The aim of the text is to give an account of the journalistic work of the Aurora de Chile, in the specific context of the early republican. Such work is enrolled in development from the model of doctrinal journalism, which was predominantly in Latin America throughout the 19th century. This research analyzed all the numbers published by the newspaper, unveil its formal structure, the themes selected, source of their information and their journalistic decisions explicit criteria, complemented with the study of books and articles relating to the topic. The text shows the deployment by the medium, in its purpose of helping the formation of a public space prone to the full independence of the country.
\end{abstract}

Keywords: History Chilean journalism; century XIX; model doctrinal journalism; Aurora de Chile.

Sumario. 1. Introducción. 2. Los primeros periódicos chilenos. 3. Los artículos doctrinarios en la Aurora de Chile. 4. Las informaciones y las noticias en la Aurora de Chile. 5. El modelo periodístico de la Aurora de Chile. 6. Conclusiones. 7. Referencias bibliográficas.

Cómo citar: Santa Cruz Achurra, Eduardo (2017): "La Aurora de Chile y los orígenes del periodismo chileno (1812-1813)", en Estudios sobre el Mensaje Periodístico 23 (1), 615-629.

1 Universidad de Chile.

E-mail: esantacr@uchile.cl 
"La voz de la razón y de la verdad se oirán entre nosotros después del triste e insufrible silencio de tres siglos"

(Aurora de Chile, Prospecto, 12 de febrero de 1812)

\section{Introducción}

El incipiente periodismo latinoamericano existente en el periodo colonial ${ }^{2}$ (Álvarez y Martínez, 1992) fue acelerado en su crecimiento por los procesos independentistas y de nacimiento de las nuevas repúblicas, los que crearon condiciones para que la prensa asumiera un rol privilegiado como instrumento de las facciones que se disputaban el nuevo poder. Sin embargo, dada la configuración de la estructura económico-social, el desarrollo periodístico mencionado contribuyó fundamentalmente al crecimiento de un espacio público propio de las elites oligárquicas criollas, en buena medida depositarias de un monopolio de la ilustración y la educación y, junto con ello, del ejercicio del poder y la práctica de la política.

Señala Myers (2004) que no existía en la región un potencial número de lectores relativamente amplio y socialmente diverso; por el contrario, la realidad más bien presentaba una altísima proporción de analfabetos que, en algunas regiones, fácilmente podía llegar al 90\% de la población, lo que debía sumarse a la pluralidad lingüística, étnica y socio-cultural, haciendo ilusoria por mucho tiempo la circulación masiva de los nuevos periódicos. De modo que el posible impacto de ellos sólo sería posible al interior de las elites, e incluso muchas veces, en sólo una fracción de ella.

La necesidad de influir en el naciente, aunque restringido espacio de debate político e ideológico, fue generando el surgimiento de un tipo especial de periódico que llegó a constituirse en una suerte de modelo, que ha sido calificado como "prensa doctrinaria" (Santa Cruz, 2010) la que se caracterizó por entregar una interpretación de la realidad, a partir de ciertos marcos doctrinarios e ideológicos como énfasis predominante, y en que la actividad informativa del medio tenía por objetivo central abastecer de ejemplos y referencias a dicha labor divulgadora. De modo que es posible afirmar que:

“...discutir fue el objetivo de la prensa del siglo XIX. Decir que esta prensa era política, de opinión o partidaria sería una redundancia. Aunque informara, esa distaba de ser su meta. La prensa irrumpió con fuerza en América Latina con los conflictos políticos e ideológicos que rodearon la Independencia y continuó siendo a lo largo del siglo, y aun entrando en el siguiente, una de las principales formas de hacer política" (Alonso, 2004: Introducción).

Sin embargo, es posible sostener la sospecha de que no se limitaban a ser, ni eran concebidos solamente como simples vehículos para la difusión de ideas o puramente valorados por sus atributos persuasivos para con sus eventuales lectores:

\footnotetext{
2 Entre otros cabe mencionar en México a la Gaceta de México y Noticias de Nueva España (1722) y Mercurio Mexicano (1739); en Guatemala, la Gaceta de Guatemala (1729); en Perú, la Gaceta de Lima (1715), El Mercurio Peruano (1791) y El Telégrafo Peruano (1795); en Cuba, la Gaceta de La Habana (1764); en Colombia, Papel Periódico de Santa Fe de Bogotá (1791).
} 
"Más decisiva aún era su capacidad material para generar "hechos" políticos (sea orquestando campañas, haciendo circular rumores, etc.), en fin, "operar" políticamente, "intervenir" sobre la escena partidaria sirviendo de base para los diversos intentos de articulación (o desarticulación) de redes políticas” (Palti, 2004: 177).

Sigue diciendo el autor, que este tipo de periodismo doctrinario aparece, simultáneamente, como un modo de "discutir" y de "hacer" política: "la prensa periódica no sólo buscaba "representar" a la opinión pública, sino que tenía la misión de constituirla como tal" (Idem: 180).

Por su lado, Chile no conoció en el periodo colonial de la existencia de periódicos y fue el proceso emancipatorio el que creó las condiciones para la aparición de una primera experiencia, como lo fue la Aurora de Chile:

"para apreciar debidamente el valor de ese periódico, es preciso transportarse por la imaginación a la época en que apareció y recordar que Chile, privado hasta entonces de una imprenta y con muy escasas comunicaciones con el exterior, no conocía más publicaciones de ese orden que las que llegaban de España y de las otras colonias" (Barros Arana, 1887: 561).

El presente texto presenta una investigación sobre este medio que intenta dar cuenta de sus estrategias periodísticas para instalarse en un contexto particularmente complejo y conflictivo como fue el de la llamada Patria Vieja, periodo inicial del proceso de independencia de Chile y que abarca de 1810 a 1814, año en que transitoriamente se repuso el poder colonial, luego del combate conocido como el Desastre de Rancagua. El punto de vista que se ofrece es la concepción de la prensa no como puro reflejo o instrumento de lógicas exteriores a ella, sino como un actor socio-cultural que opera desde sus propias instalaciones ideológicas y culturales, construyendo y difundiendo sentidos sobre lo social. No se trata, tampoco, de reclamar para la actividad de la prensa supuestas autonomías autárquicas. Por el contrario, se trata de poner el énfasis en las articulaciones y relaciones, siempre complejas cuando no conflictivas, con otros espacios y los modos de discurso que de ellos emanan.

En ese marco, a través de sus estrategias difusoras, que naturalmente apuntan en dirección a sus propios objetivos, los diarios y revistas buscan su instalación en el medio socio-cultural y de mercado, presentando un cierto perfil y segmentando un cierto público, todo lo cual entra en relación más o menos fluida o conflictiva con la realidad social, política, cultural y económica de un período o época determinada.

Hemos analizado todos los números que publicó la Aurora de Chile, buscando determinar su estructura formal, los ámbitos temáticos, las técnicas, géneros y formatos periodísticos utilizados y, especialmente, la concepción de prensa que se puede inferir de lo anterior. Es decir, analizar el periódico no solamente como fuente documental de un periodo o una ideología determinada, cuestión que ha predominado en los estudios que se han realizado sobre él, (Montt, 1918; Amunátegui, 1854; Téllez, 1945; Santana, 1938), como incluso en el clásico estudio de Silva Castro sobre la historia de la prensa chilena (Silva Castro, 1958). 


\section{Los primeros periódicos chilenos}

Corría el 16 de enero de 1812 cuando un decreto de la Junta de Gobierno, que presidía José Miguel Carrera y que integraban también José Nicolás de la Cerda y Manuel Manso, nombró a Fray Camilo Henríquez a cargo de la edición de un periódico con un sueldo de 600 pesos anuales:

"Fue durante el periodo de gobierno relativamente breve de Carrera cuando empezaron a actuar a favor de la revolución varias influencias nuevas e importantes. La más significativa de éstas fue, evidentemente, la imprenta. Por primera vez en la historia de Chile, las ideas se pudieron imprimir y divulgar en escala bastante grande dentro de la nación" (Collier, 1977: 94).

En poco tiempo, circularon publicaciones de distinto tipo, tales como proclamas, manifiestos, edictos y otros documentos, junto a los periódicos que fueron publicados entre 1812 y 1814. El primero de estos últimos fue el encargado a Fray Camilo. Casi un mes después del decreto mencionado, el 12 de febrero, circuló el llamado "Prospecto", en que se explicaba el carácter y los objetivos del que era el primer periódico editado en el país, bajo el epígrafe "Periódico ministerial y político". El texto comenzaba señalando que: "Está en nuestro poder, el grande, el precioso instrumento de la ilustración universal, la Imprenta. Los sanos principios, el conocimiento de nuestros eternos derechos, las verdades sólidas y útiles van a difundirse entre todas las clases del Estado". Agregaba, luego que "se echaba de menos un Periódico que las anunciase y difundiese, que generalizase las ideas liberales; consolidase la opinión y comunicase a todas las Provincias las noticias del día" (Aurora de Chile, Prospecto, 12 de febrero de 1812).

Junto a ello se entregaban también datos prácticos, como que el periódico se vendería en el local del Correo y en el Almacén de don Roque Allende y que el valor de las suscripciones "en la Capital importará seis pesos, en lo interior del Reino nueve, y fuera de él, doce". Se trataba de precios semestrales, lo que llevó a Barros Arana a afirmar que se trataba de un "valor subidísimo que solo puede explicarse por el reducido número de suscriptores, porque aunque el periódico era bastante leído, y circulaba de mano en mano, la edición no pasaba de doscientos ejemplares, que bastaban para las oficinas de gobierno y para los suscriptores" (Barros Arana, 1887: 559).

Al día siguiente, jueves 13 de febrero de 1812, apareció lo que es oficialmente su primer número, con la estructura que se hizo común a las cuatro páginas a dos columnas de que disponía el medio. Por una parte, un artículo de carácter ideológico que, en este caso, se tituló "Nociones fundamentales sobre los derechos de los pueblos" y, por otra parte, un grupo de notas en que se reproducían informaciones extraídas fundamentalmente de diarios extranjeros. Para esta primera edición se trataba de una nota basada en la Gazeta de Río de Janeiro, en su edición del 20 de noviembre de 1811 y otras dos elaboradas a partir de las ediciones del 3 y 5 de septiembre de 1811, del The Times, de Londres, es decir con tres y cinco meses de "atraso", respectivamente.

El papel de Fray Camilo en la producción del periódico fue central. Según Montt, "Henríquez escribió en casi todos los números, en algunos dos y hasta tres artículos, aparte de las traducciones de noticias tomadas a las gacetas extranjeras" (Luis Montt, 
1918: 38.). Agrega que en ocasiones firmaba los artículos o usaba seudónimos como Cayo Horacio, Patricio Curiñancu y otros. En la edición del jueves 27 de agosto de 1812 se hacía explícito lo anterior, al señalar que "Cuanto en las Auroras está sin el nombre, o cifra de sus autores, es obra del editor" (Aurora de Chile, n ${ }^{\circ} 29,27$ de agosto de 1812).

Sin embargo, es un error suponer que el periódico fue fruto solamente de la labor de Henríquez. En la medida en que era un vocero oficial del gobierno, este mantuvo un cierto control sobre la publicación, lo que, siguiendo a Silva Castro, no estaría lejano a desacuerdos con ciertos contenidos y opiniones de Fray Camilo, considerados demasiado radicales y que, por lo tanto, podrían molestar a los sectores más moderados, quizás todavía mayoritarios a esa altura de los acontecimientos.

Ello se hizo explícito cuando, según consigna Silva Castro, en agosto de 1812 la Junta de Gobierno, ahora integrada por Carrera como Presidente, José Santiago Portales y Pedro Prado como vocales, nombró a una comisión compuesta por Juan Egaña, Francisco Antonio Pérez, Pedro Vivar y Manuel de Salas con un rol de supervisión de la Aurora de Chile (Silva Castro, 1958: 18). Según Silva Castro, Henríquez replicó no publicando dicho decreto en las páginas del periódico, como sí ocurría con todos los documentos oficiales de este tipo y, además, publicó extractos del célebre discurso de Milton sobre la libertad de prensa, pronunciado en el Parlamento de Inglaterra (Aurora de Chile, $\mathrm{n}^{\mathrm{o}} 30,3$ de septiembre de 1812).

Más aún, poco después el gobierno dictó un decreto fechado el 12 de octubre de 1812 y publicado en la edición del 15 del mismo mes, en que se establecía la censura previa a las ediciones del periódico a cargo del Tribunal de Apelaciones. El fundamento que establecía el decreto gubernativo sobre esta medida era el siguiente:

"Debiendo conciliarse el libre ejercicio de las facultades del hombre con los derechos sagrados de la religión y el estado cuyo abuso funesto e inconsiderado puede envolvernos en desgracias, que no calcula la animosidad afogada de los amantes exaltados de la libertad, y deseando cortar todo motivo de queja entre los estados amigos y decididos protectores de la nación" (Aurora de Chile, $\mathrm{n}^{\circ} 36,15$ de octubre 1812).

Como se puede ver, el texto realiza insinuaciones que no son suficientemente explícitas como para dilucidar con claridad las causas de la medida. Como una simple hipótesis puede señalarse que en la edición anterior, Fray Camilo, bajo el seudónimo de Cayo Horacio, había publicado un artículo que, excepcionalmente, ocupaba todas las páginas llamando encendidamente a declarar de una vez la independencia: "Tiempo es ya de que cada una de las provincias revolucionadas de América establezca de una vez lo que ha de ser para siempre: que se declare independiente y libre" (Aurora de Chile, $\mathrm{n}^{\mathrm{o}} 35,8$ de octubre de 1812), agregando un elemento que pudo haber generado más de algún resquemor, al decir que "una de las circunstancias que más nos convida a dar el paso necesario de la declaración de independencia, es la actual impotencia de los poderes de Europa para oponerse a nuestra libertad" (Idem), remarcando que nada se debía esperar ni del triunfo de Francia, ni del de España, ni de Inglaterra, juicios a los que parecen aludir los fundamentos del decreto de censura. 
Después de aparecer regularmente los días jueves de cada semana un total de 56 números, sin aviso previo y sin mayor explicación, el $1^{\circ}$ de abril de 1813 se publicó la última edición de la Aurora de Chile. El contexto político era particularmente grave. Pocos días antes había desembarcado la expedición al mando del Brigadier Antonio Pareja, enviada por el Virrey del Perú, compuesta de cinco barcos que traían fundamentalmente oficiales españoles y recursos para armar un ejército, para lo cual se dirigió primero a Chiloé y Valdivia, donde recogió tropas milicianas locales y luego desembarcó en Talcahuano, tomando Concepción el 29 de marzo y avanzando hasta Chillán y Linares. Ello motivó la marcha al sur de las tropas patriotas, al mando de José Miguel Carrera, abriendo lo que se conoce como la campaña de la Patria Vieja, que culminó en la derrota patriota en Rancagua, en octubre de 1814.

La Aurora de Chile reprodujo en su último número la proclama del "Gobierno a los Pueblos" en que se informaba del viaje de Carrera y de las tropas al sur a enfrentar la invasión y se señalaba que "ya se borró del diccionario político de Chile la funesta voz "moderantismo" (Aurora de Chile no 12, 1 abril de 1813).

Pocos días después, el 6 de abril comenzó la publicación de El Monitor Araucano, el que mantuvo el carácter de órgano oficial y la misma redacción de la Aurora de Chile, incluyendo el aporte de Fray Camilo. Sin embargo, al decir de Silva Castro, este nuevo medio, que circuló hasta el 30 de septiembre de 1814, habría tenido un carácter político más práctico, propagandeando las medidas y decretos de gobierno y motivando y exhortando al apoyo del gobierno comprometido ahora en la lucha militar contra las invasiones enviadas por el Virrey del Perú. De hecho, dicho autor, hace el siguiente parangón entre uno y otro medio:

"Impresiona a primera vista el cambio de tamaño. Después del pliego grande de la Aurora, distribuido en dos columnas de composición, se ve mezquino, acaso vergonzante, el nuevo periodiquito, que puede ser deslizado en el bolsillo sin que sea necesario plegarlo" (Silva Castro, 1958: 33).

Por otro lado, el 7 de agosto de 1813 apareció el tercer periódico de la Patria Vieja, el Semanario Republicano, dirigido y creado por Antonio José de Irisarri, quien había participado en la Aurora de Chile y que se había convertido en opositor y crítico del gobierno de Carrera, con lo que podría considerarse como una primera experiencia de prensa independiente y opositora. En él también jugó un papel importante Fray Camilo Henríquez, especialmente desde octubre de 1813 en adelante, desarrollando otra faceta, la de la elaboración de versos satírico-políticos.

\section{Los artículos doctrinarios en la Aurora de Chile}

Como se dijo antes, un componente clave y central en la estructura de la Aurora de Chile fue la publicación de artículos de corte doctrinario e ideológico, la mayor parte de los cuales fue redactado por Henríquez:

"Sobre una gran variedad de materias, derecho constitucional, inmigración, hacienda pública, policía, civilización de indígenas, instrucción pública, industria y comercio, publicó la Aurora de Chile estudios que si no pueden llamarse sazonado, revelan cierta extensión de conocimientos y abrirán horizontes nuevos a las aspiraciones de la opinión liberal” (Barros Arana, 1887: 561). 
Presentes en casi todas las ediciones, hemos podido clasificar 36 de ellos, algunos de los cuales continuaron en la edición siguiente a la de su aparición. Es posible diferenciar al menos tres tipos de trabajos. Uno primero constituido por artículos de corte general, en los que se plantea una discusión conceptual e ideológica de carácter teórico y de aplicación universal, pero que claramente está destinado a abastecer de razones y argumentos en esa dimensión a los partidarios de avanzar con decisión hacia la independencia plena. Un tema recurrente en ese sentido es el de la teoría política, en la perspectiva de una nueva organización estatal, a partir de la instalación de un régimen republicano.

Es el caso, por ejemplo, de "Nociones fundamentales de Derecho Público. Orígenes y fundamentos de la soberanía" (Aurora de Chile $\mathrm{n}^{\circ}$ 14, 14 de mayo de 1812), el que fue seguido de otro titulado "De las diversas formas de gobierno. De los gobiernos simples y regulares" (Aurora de Chile $\mathrm{n}^{\circ} 16,28$ de mayo de 1812). En ellos se explica, por ejemplo, que se puede hablar de un gobierno democrático "cuando la soberanía reside en la asamblea general de todos los ciudadanos de modo que cada uno de ellos goza del derecho de sufragio", y se lo diferencia del gobierno de una aristocracia en que la soberanía reside solo en un grupo de ciudadanos escogidos o de una monarquía, en que reside única y exclusivamente en un solo hombre.

Meses después se publica un artículo sin título en que se debate extensamente, ya que ocupará espacio en dos ediciones consecutivas, acerca de la discusión necesaria sobre el carácter que debe asumir el Poder Legislativo. A partir del análisis de las experiencias de Estados Unidos, Gran Bretaña y "la Francia revolucionaria" llega a la conclusión de la necesidad de un sistema bicameral (Aurora de Chile núms. 5 y 6 , 4 y 11 de febrero de 1813$)^{3}$. En la misma dirección, en su última edición y junto a la proclama de Carrera llamando a enfrentar la invasión realista, se publica un artículo sin título ni firma en que se aborda la discusión sobre la constitución del sistema judicial, prefiriendo aquel basado en el sistema de jurados por sobre el heredado del régimen colonial. También se abordan otro tipo de temas, aunque en el mismo plano. Es el caso de un extenso artículo, igualmente sin firma ni título, en que se reflexiona sobre el impacto histórico de los procesos revolucionarios, señalando que:

"Las revoluciones [...] se asemejan a esos grandes terremotos, que rasgando el seno de la tierra descubren sus antiguos cimientos, y su estructura interior: trastornando los imperios manifiestan la organización profunda y los resortes misteriosos de la sociedad" (Aurora de Chile no 23, 16 de julio de 1812).

En la continuación del artículo, en la edición siguiente, se aborda también la influencia de esos procesos en la transformación de las personas y en cómo hace posible la emergencia de conductas que, tal vez, no ocurrirían en circunstancias comunes. Una causa justa dice es la que hace posible el heroísmo, para lo que hace referencia a una serie de ejemplos históricos, comenzando con los "300 espartanos", agregando que: "En las revoluciones se agrandan las almas, se muestran los héroes [...] En las revoluciones se ven esos hechos inmortales, esos ejemplos de generosi-

Es necesario aclarar que, a contar del primer número publicado en 1813, la numeración de los ejemplares volvió al $n^{\circ} 1$. 
dad admiración de las generaciones futuras" (Aurora de Chile nº 24, 23 de julio de 1812).

También se puede destacar en esta dirección una trilogía firmada por A.J.I. (lo que correspondería a Antonio José de Irisarri), formada por los artículos "De la opinión pública" (Aurora de Chile núms. 33 y 34, 24 de septiembre y 1 de octubre de 1812), en el que el autor, polemizando implícitamente con Henríquez, señala que los pueblos "lo único que buscan y lo único que les interesa es que se les gobierne con sabiduría y con beneficencia: todo lo demás ni lo entienden ahora, ni lo entenderán jamás". El segundo texto lleva por título "Discurso dirigido por la Aurora de Chile a los Patriotas de nombre" (Aurora de Chile $\mathrm{n}^{\circ} 37,22$ de octubre de 1812) y en el que el autor afirma que la Patria no es sino un conjunto de hombres reunidos "bajo un gobierno y unas leyes que a todos favorecen igualmente", según las ideas de la razón y la sabiduría y no "el suelo, ni los cerros, ni los ríos, ni los árboles, ni las casas". El tercer artículo lleva por título "Discurso sobre la necesidad de sostener el sistema de la América y sobre la injusticia de sus enemigos" (Aurora de Chile $\mathrm{n}^{\circ} 38,29$ de octubre de 1812).

Otro tipo de artículos doctrinarios es el que se refiere más o menos directamente a la realidad que vivía la sociedad chilena, sea para analizar alguno de sus aspectos o para recomendar medidas y políticas de transformación de ella. En esa dirección podemos destacar los siguientes: "Observaciones sobre la población del Reino de Chile" (Aurora de Chile $\mathrm{n}^{\circ}$ 3, 27 de febrero de 1812), en que se argumenta que no existía ninguna razón física para explicar "el atraso de la población de Chile", sino que la explicación estaba en causas políticas y morales y que las "encontramos en la imperfección de la agricultura, en el atraso de la industria, comercio, policía, ciencias exactas y naturales, artes útiles, legislación". En ese mismo sentido, en el número siguiente se hace cargo de la situación de la salud e higiene públicas, señalando que:

"Parece que entre las principales causas de las enfermedades que padecen las poblaciones, deben numerarse las siguientes: desaseo y miseria de la plebe, inmundicias en las calles, detención de las aguas, corrupción de los cadáveres dentro de la misma población, reunión de muchas personas en lugares de poca ventilación, principalmente si hay fuego y luces" (Aurora de Chile no 4, 5 de marzo de 1812).

De este modo, hay una serie de temas de diversa índole que fueron analizados, tales como "Civilización de los indios"(Aurora de Chile $\mathrm{n}^{\circ}$ 12, 30 de abril de1812), "Cultura del tabaco en Chile" (Aurora de Chile no 16, 28 de mayo de 1812), "Plan de organización del Instituto Nacional" (Aurora de Chile $\mathrm{n}^{\circ} 19$ y 20, 18 y 25 de junio de 1812) $)^{4}$, "Reflexiones acerca del derecho que tienen a las Américas los españoles europeos y americanos que actualmente las habitan y acerca de la conducta de la Metrópoli para con ellos" (Aurora de Chile $\mathrm{n}^{\mathrm{O}}$ 19, 18 de junio de 1812), entre otros.

Finalmente, se pueden destacar también, tres artículos de Fray Camilo, referidos a la necesidad urgente de la declaración de independencia. En el primero de ellos, señalaba que "Un pueblo que depende de una metrópoli, no figura entre las naciones, no es más que una provincia [...] es un absurdo creer que exista en algún punto de la

$4 \quad$ Los artículos explican extensamente la organización y objetivos de la institución, así como contenidos de cada asignatura y horarios de los planes de estudios, entre otros detalles. 
tierra la libertad civil sin la libertad nacional" (Aurora de Chile $\mathrm{n}^{\circ}$ 28, 20 de agosto de 1812). En el número siguiente publica con su firma el texto titulado,"Nunc animis opus, Aenea, nunc pectore firmo", en el que llama a los "Pueblos Americanos" a actuar con más resolución en la lucha por la Independencia, terminando su análisis y exhortación con la frase "Hasta cuándo pensáis? Resolved: bastante se ha pensado" (Aurora de Chile $\mathrm{n}^{\circ}$ 29, 27 de agosto de 1812). El tercero de ellos es el antes citado artículo publicado en el número 35, del 8 de octubre del mismo año.

Un tercer tipo de artículos, menos numeroso, consiste en tomar un hecho o un proceso acontecido en otro lugar del mundo y/o en otra época y que sirva como ejemplo para extraer lecciones o enseñanzas aplicables a la situación política nacional. Es el caso del artículo "Noticias relativas a los Estados Unidos de Norteamérica", publicado en dos ediciones, en el que se describe la situación del nuevo país, con datos y cifras detalladas de su población, ciudades, comercio, etc. para resaltar el progreso logrado con la independencia:

"Después de la revolución las mejoras de los Estados Unidos han sido rápidas e importantes: se han edificado ciudades, se han abierto caminos, se han construido fuentes y otras obras magníficas [...] todos saben leer y escribir y en casi todos los estados se han establecido escuelas públicas, de modo que el más pobre no pasa por el dolor de ver criarse sus hijos en la ignorancia. En todas las casas aún las más pobres, se encuentran libros y gazetas; todos leen, todos piensan y todos hablan con libertad" (Aurora de Chile núms. 12 y 13, 30 de abril y 7 de mayo de 1812).

En definitiva, y ajustándose a las características propias del modelo de prensa doctrinaria, los contenidos de este tipo de artículos no son solamente disquisiciones teóricas o ideológicas, que no se refieran ni aludan a la situación política específica en que se desenvuelve la vida del periódico, sino que, por el contrario, en muchas ocasiones están orientados a entregar una lectura que explique aquella o que justifique medidas o políticas que el medio en tanto actor político sugiere o promueve prácticamente.

\section{El tratamiento de la información y las noticias en la Aurora de Chile}

Como hemos señalado, si bien la tendencia predominante del modelo de prensa doctrinaria es la discusión teórica e ideológica sobre la realidad a la que se refiere y en la que actúa, eso no significa que la información esté totalmente ausente. Si bien su papel es subordinado, su presencia es importante y permanente. Ello fue particularmente evidente en tiempos de la Patria Vieja, cuando el desarrollo y perspectivas del proceso político que se vivía estaban condicionados y en buena medida determinados por los acontecimientos que se vivían en España, a raíz de la invasión napoleónica y la consiguiente destitución del Rey Fernando VII.

En el caso chileno, dado que ello constituyó parte importante de la fundamentación para legitimar los primeros pasos hacia la autonomía y, luego, la independencia, sobre todo en esos primeros años de la década, la marcha de la guerra en la Península afirmaba las pretensiones y posibilidades de uno u otro sector y de las posiciones políticas acerca de la relación con la Metrópoli. Lo dicho está clara y directamente 
planteado en las páginas del periódico, cuando se pregunta si la duración de la guerra en la Península favorecía o no a las "provincias revolucionarias de América":

"La duración de estos conflictos es un tiempo muy precioso para las provincias revolucionadas del nuevo mundo; y apenas habrá quien ponga en duda que mientras más tiempo duren, se les ofrece más proporción, más facilidad para concluir y consolidar la gran obra que han emprendido [...] mientras los restos de una nación moribunda se esfuerzan por resistir al poder colosal de un Imperio [...] pueden nuestras provincias hacerse naciones y pararse en un pie formidable" (Aurora de Chile $\mathrm{n}^{\mathrm{o}} 25,30$ de julio de 1812).

De allí que las noticias sobre los sucesos europeos no venían solamente a satisfacer la curiosidad o un ánimo de "estar al día", sino que repercutían directamente en la marcha política interna. La revisión de las páginas de la Aurora de Chile hace evidente lo anterior, así como el tratamiento intencionado que el periódico le da a la información que recibía desde el exterior.

Hemos seleccionado un total de 131 notas informativas que cumplen con el requisito de entregar datos sobre algún hecho determinado y que se inscriben en procesos o situaciones conocidas. Estas notas fueron clasificadas, en primer término, de acuerdo a su contenido, es decir, fueron ordenadas según el tema de que tratan y, además, fueron clasificadas de acuerdo a la fuente de origen. Cabe señalar que muchas de estas notas no tienen títulos, pero si hay elementos gráficos de la diagramación de la página que las destacan y les dan singularidad suficientemente distinguible.

Casi la mitad de ellas (66) dice relación con informaciones que daban cuenta de la marcha de lo que se denominaba en el periódico, la "Revolución Americana". Hay dos de ellos especialmente destacables, ya que constituyen una suerte de reportajes acerca del "estado de la revolución en América". El primero, publicado en dos ediciones sucesivas, se titulaba "De las provincias revolucionadas de América" (Aurora de Chile núms. 29 y 30, 27 de agosto y 3 de septiembre de 1812) y en él se pasaba revista a lo sucedido en Quito, Colombia, Venezuela y México y se analizaba a partir de ello las perspectivas de desarrollo del proceso en esas regiones. Poco después, se publicó un artículo semejante, sin firma, en que se anunciaba un balance de esta:

"revolución americana que lleva en todas partes como dos años [...] y en las más de ellas ofrece un aspecto no muy diferente del que tuvo en sus principios; riesgos que pudiesen haberse aniquilado; una marcha lenta e incierta; fluctuación entre esperanzas y temores; irresolución y a veces frialdad. En muy pocos puntos se presenta robusta y majestuosa" (Aurora de Chile n ${ }^{\circ} 33,24$ de septiembre de 1812).

El restante de las notas se refería a hechos puntuales ocurridos en el Alto Perú (17), Buenos Aires (10), Montevideo (10), México (9), Venezuela (8), Guayaquil, Haití y Perú (3) y una sobre Paraguay. Una especial atención se dedica a las campañas de las tropas bonaerenses en el Alto Perú y el norte de la actual Argentina, bajo la dirección del General Manuel Belgrano, celebrando algunas de sus victorias, como la de las batallas de Suipacha (Aurora de Chile $\mathrm{n}^{\circ} 27,13$ de agosto de 1812) o Catamarca (Aurora de Chile n ${ }^{\circ}$ 36, 15 de octubre de 1812); la del General Arenales 
al tomar la ciudad de Salta (Aurora de Chile $\mathrm{n}^{\circ} 40,12$ de noviembre de 1812) o la del General José de San Martín, en San Lorenzo (Aurora de Chile ${ }^{\circ}$ 9, 11 de marzo de 1813).

Lo sucedido en las campañas sobre el Alto Perú provocaba un interés manifiesto entre los patriotas chilenos, por razones obvias. Las principales relaciones políticas, económicas, sociales y culturales del país eran con las provincias del Plata, por un lado y con el virreinato de Lima, por otro. Las victorias de las tropas de Buenos Aires, vistas como las aliadas naturales, sobre las del Virrey Abascal, no podían sino influir positivamente en la marcha del proceso chileno. Por ello, la Junta de Gobierno chilena celebró con gran pompa un Te Deum solemne para celebrar las victorias de Belgrano. La ceremonia se llevó a cabo el 25 de octubre en la Iglesia de La Merced, con la asistencia de la Junta presidida por José Miguel Carrera, jefes militares, corporaciones y numeroso público "en demostración del regocijo con que los Patriotas de Chile celebran los triunfos de sus hermanos de Buenos Aires por la completa victoria que el 24 de Septiembre obtuvieron sus armas" (Aurora de Chile $\mathrm{n}^{\mathbf{0}}$ 38, 29 de octubre de 1812).

De igual manera, la marcha de las acciones militares en la entonces llamada "Banda Oriental", hoy Uruguay, está presente en diversos números, desde una victoria del General Artigas contra tropas portuguesas en 1811(Aurora de Chile $\mathrm{n}^{\mathrm{o}} 2$, 20 de febrero de 1812), así como el sitio que las fuerzas patriotas, primero al mando de Artigas y luego del General Rondeau, sostuvieron sobre Montevideo. También cabe destacar la atención que se le da a los sucesos de México, primero sobre el levantamiento y posterior derrota y muerte del Cura Manuel Hidalgo, "tantas veces anunciada, cuantas apetecida por los enemigos de la libertad de la América" (Aurora de Chile $\mathrm{n}^{\circ} 32,17$ de septiembre de 1812), como también a los combates de las tropas del cura Morelos, de cuyos triunfos en Acapulco y Veracruz se informa citando periódicos estadounidenses (Aurora de Chile $\mathrm{n}^{\circ} 8,4$ de marzo de 1813).

Más atrás mencionamos la repercusión que tuvo en Chile la derrota de los revolucionarios de Venezuela y la caída de Caracas en manos de las tropas realistas en 1812. El proceso en esa región había merecido la atención del periódico desde su aparición. Ya en la edición $\mathrm{n}^{\mathrm{o}} 6$ se consignaban informaciones sobre la toma de la ciudad de Valencia por las tropas al mando de Francisco de Miranda y en el número siguiente se reprodujo íntegramente la "Declaración de Independencia de las provincias de Venezuela" (Aurora de Chile $\mathrm{n}^{\circ}$ 7, 26 de marzo de 1812), de modo que no es extraño el espacio que se le concedió a los sucesos de su derrota y los efectos producidos en nuestro país.

El segundo ámbito temático al que se le da amplio espacio, con 40 notas, es el que tiene que ver con las guerras napoleónicas y la situación política en Europa. La mitad de ellas, a su vez, son informaciones específicas de la guerra en España y la mayoría de ellas ponen énfasis en la situación que sería desesperada de las fuerzas españolas y sus aliados ingleses, como por ejemplo se manifiesta en la edición $\mathrm{n}^{\mathrm{o}} 31$ en que se reproduce un texto firmado por "D.B." y fechado en febrero (siete meses antes), y en que se señala que la situación de las Cortes de Cádiz es angustiosa y que ante el inminente ataque francés a este "último reducto", se habla de trasladarlas a La Habana (Aurora de Chile $\mathrm{n}^{\circ}$ 31, 10 de septiembre de 1812).

Por otro lado, el periódico consigna también un espacio a noticias de carácter nacional que no tienen directa relación con el proceso político, sino que nos hablan más bien de la cotidianidad, así como de la dimensión de gestión y administración 
del gobierno. Cabe mencionar que en no menos de cinco ocasiones se informa sobre la situación del Hospital San Juan de Dios, de la capital, así como sobre una campaña de vacunación contra la viruela que organiza la Junta de Gobierno, en Santiago, y sus estadísticas mes a mes. También hay algunas informaciones de carácter económico y referidas a medidas de fomento a la minería y una relacionada con dos Parlamentos realizados por el Intendente de Concepción, Coronel Pedro José Benavente con mapuches en la Plaza de Arauco, con el Butalmapu de la Costa, al que asistieron unos 50 caciques y con mapuches de Angol, a los que acudieron 63 caciques. El periódico señala que los mapuches reconocieron la "autoridad central de la Patria" y que "prometieron prestar una cooperación activa y enérgica" a la defensa de esta (Aurora de Chile $\mathrm{n}^{\mathrm{o}}$ 6, 11 de febrero de 1813). Finalmente, se puede señalar que en tres ocasiones la Aurora publicó pronósticos del estado del tiempo, los que según Barros Arana provenían de las “observaciones meteorológicas que hacía don Felipe Castillo Albo, comerciante español aficionado a los estudios de ciencias naturales. Esas observaciones, que eran una novedad para los contemporáneos, son regularmente prolijas, y aunque deficientes, pueden ser utilizadas" (Barros Arana, 1887: 561).

\section{EI modelo periodístico de la Aurora de Chile}

La experiencia de la Aurora de Chile pone de manifiesto cómo las relaciones y articulaciones que se establecen entre el medio y su contexto histórico son muy importantes para determinar la inserción del medio como actor político y cultural en dicho contexto. De parte de Fray Camilo Henríquez hay una intención explícita y evidente porque esta primera manifestación del periodismo chileno jugara un papel activo y protagónico en la formación de una opinión pública favorable a la plena emancipación.

Ese rol político del periódico tenía que situarse en consonancia con un marco mayor al de la situación política nacional, que era el proceso mayor que recorría y sacudía a todas las colonias hispanoamericanas, el que, a su vez, dependía de lo que estaba sucediendo en Europa y, especialmente, en la Península Ibérica.

Esta relación de la Aurora de Chile con contextos mayores, a través de distintos medios, tales como periódicos, cartas y otros documentos, ha sido estudiada como parte de lo que se ha llamado "periodismo transfronterizo", como forma de globalización incipiente (Doren, 2014). A lo que se refiere es a que este periodismo no se desarrollaba solamente al interior de los nacientes estados-naciones, luego de la Revolución Francesa, tanto en Europa como en América, sino que existían procesos en que medios de distintos países, regiones e incluso continentes se alimentaban de informaciones unos a otros y se estudia a la Aurora de Chile como expresión de aquello.

En el caso de la Aurora de Chile es particularmente notorio el interés de conseguir informaciones, a través de los más variados recursos. Sin embargo y por razones obvias de aislamiento geográfico y de que aún no se contaba con tecnologías que facilitarían las cosas avanzado el siglo, tales como el telégrafo y el cable submarino, el medio no estaba en condiciones de seleccionar o elegir absolutamente sus fuentes exteriores, ni menos de tener un conocimiento directo de esos acontecimientos, por la vía de lo que décadas más tarde se conoció como el corresponsal, figura profesional que apareció cuando ya se están desarrollando las condiciones que condujeron 
en poco tiempo a la aparición de lo que se conoce como periodismo liberal moderno (Idem).

En este caso, Fray Camilo y la Aurora de Chile más bien parecen recurrir a lo que se podía conseguir por distintas vías. Hemos podido determinar y examinar un total de 144 notas informativas sobre sucesos externos en los 56 números publicados por el periódico. De ellas, prácticamente la mitad no tiene una fuente que identifique la procedencia. Sin embargo, la otra mitad si la establece explícitamente.

De esta manera, podemos mencionar que existen, al menos, 35 notas que reproducen material contenido en otros periódicos. De ellos, se trata de 18 periódicos ingleses: ocho notas son tomadas de The Times y cinco de The Morning Chronicle, entre las principales; las otras provienen de The Sun, la Gazeta de Londres, Liverpool Saturday Advertises y Bell's Weekly Messenger. De periódicos de Estados Unidos provienen 11 notas, destacando The Sun, de Baltimore y The Register, de la misma ciudad, además de la Gazeta de Filadelfia, la Gazeta de Nueva Jersey, el Columbian Centinel y el Independent Chronicle. Llama la atención la poca presencia de medios de la región; hay una mención a la Gazeta Ministerial, de Buenos Aires, dos a la Gazeta de Río de Janeiro y una al Mercurio Peruano. De hecho, las alusiones a los sucesos de México y Venezuela, por ejemplo, provienen de informaciones tomadas de diarios estadounidenses.

En el caso de lo que estaba ocurriendo en las Provincias Unidas del Río de la Plata y que provocaba gran repercusión en la política chilena, la mayoría de las informaciones provenía de cartas personales, no menos de 27 notas informativas publicadas en la Aurora de Chile y la gran mayoría referidas a sucesos de la campaña de Alto Perú o de Montevideo tienen ese origen explícito, el que es validado por el medio al calificarlo como personas "de carácter y verdad" (Aurora de Chile $\mathrm{n}^{\mathrm{o}} 1,13$ de febrero de 1812) o de "una persona de primer orden" (Aurora de Chile n' 3, 21 de enero de 1813). Junto a las cartas, un rol no menor lo jugó también la comunicación oral. La llegada de viajeros, algunos de ellos dedicados al comercio marítimo, se constituía en una fuente importante de información, no solamente porque solían traer documentos escritos, tales como periódicos o cartas, sino porque también narraban y comentaban sucesos y acontecimientos. Los barcos eran una fuente recurrente de abastecimiento de información.

Esto último nos habla de otra cuestión que es importante destacar de este flujo informativo que llegaba desde el exterior y que tiene que ver con la oportunidad de su llegada. Como señala Barros Arana, las noticias de Europa tardaban cerca de dos meses en llegar, que era lo que demoraba el barco a vela que las traía y desde Buenos Aires podían demorar un mes. Agrega que la instalación de la Junta de Gobierno de Caracas, en mayo de 1810, se conoció en Santiago de Chile recién en el mes de octubre de ese año y la noticia llegó vía Buenos Aires, donde a su vez, la habían conocido a través de un diario de Filadelfia, llegado en un barco,

La revisión de todas las notas informativas que hemos mencionado que aparecen en la Aurora de Chile, nos habla de meses de desfase entre la ocurrencia del hecho, políticamente significativo para la realidad chilena y el conocimiento por parte de la sociedad nuestra. Ello nos refiere no solamente a un manejo de las categorías de tiempo y espacio por parte del periódico muy distintas a las que desarrollará la prensa y la industria cultural en el siglo XX, por no mencionar la realidad actual, sino además de una experiencia vital cualitativamente diferente con respecto a ellas. 


\section{Conclusiones}

La Aurora de Chile ocupa un lugar en la historia del periodismo nacional no solamente por su carácter de experiencia fundacional, sino que por hacerlo inaugurando una manera de hacer periodismo que marcó el desarrollo de la prensa en nuestro país durante décadas. Generalmente se enfatiza en la importancia de este periódico, en tanto fuente documental para conocer la evolución del pensamiento emancipatorio, así como por su intención de influir en ese desarrollo.

En este trabajo hemos querido demostrar también su valor como expresión de una actividad periodística que fue capaz de articular en su despliegue una dimensión más bien universal, en lo que dice relación con su formato y el carácter de su estrategia periodística y comunicacional y, por otra parte, una dimensión específica y particular, en lo que dice relación con el rol de actor político que intentó desarrollar en el contexto que vivía la sociedad chilena.

En el primer sentido, es posible afirmar que la Aurora de Chile se inscribió claramente en lo que se ha llamado modelo de prensa doctrinaria, que constituyó la tendencia predominante en las maneras de concebir y desarrollar el periodismo, durante la mayor parte del siglo XIX, tanto en América como en Europa (Weill, 1974), inaugurando su desarrollo en nuestra sociedad. Un tipo de prensa para la que el análisis e interpretación de la realidad, a partir del despliegue de una concepción doctrinaria e ideológica, era lo central de su quehacer y para la que la labor informativa cobraba sentido, en tanto sirviera de soporte o referente para lo anterior.

Por otro lado, el particular contexto de los primeros años del proceso de emancipación con todas sus vacilaciones, contradicciones y conflictos, llevó al periódico y en especial a Fray Camilo Henríquez, como su principal mentor, a intentar la enorme tarea de ayudar a construir un espacio público ilustrado que sirviera de sostén político de la lucha por la independencia, aunque esa opinión colectiva que se quería formar y alimentar de opiniones y argumentos era solamente una pequeñísima fracción de la población, la elite oligárquica al interior de la que se libraba casi exclusivamente esa lucha ideológica.

Se puede afirmar que en el poco más de un año de existencia de la Aurora de Chile, esta logró no pocos objetivos, instaló en el público ilustrado que la leía una serie de temas y problemas que se iban planteando a medida que se trataba de construir una estructura política diferente a la colonial; informando acerca de la marcha del proceso independentista de la región ayudó a expandir el conocimiento que se tenía sobre ella; dejó objetivada la marcha de la administración y gestión estatal a través de la publicación de decretos y oficios de gobierno, en fin, colaboró a expandir un sentido común e imaginario colectivos, aunque fuera con alcances limitados a la elite. Por ello, Barros Arana, algunas décadas después, señaló que "Cuando se conoce aquel estado de cosas, no se puede dejar de admirar la labor de los primeros periodistas de Chile" (Barros Arana, 1887: 561).

\section{Referencias bibliográficas}

Álvarez, Jesús Timoteo y Martínez Riaza,Ascensión(1992): Historia de la prensa hispanoamericana. Madrid, Editorial Mapfre.

Amunátegui, Miguel Luis (1854): Biografias de Americanos. Santiago de Chile, s/e. 
Barros Arana, Diego (1887): Historia General de Chile, Tomo VIII. Santiago de Chile, Rafael Javer Editor.

Collier, Simón (1977): Ideas y Política de la Independencia Chilena. Santiago de Chile, Editorial Andrés Bello.

Doren Santander, Daniela (2014): "Redes de periodismo transfronterizo en la etapa de globalización incipiente: el caso de la Aurora de Chile". Ponencia en el I Congreso de la Asociación Chilena de Investigadores de la Comunicación, Incom.

Montt, Luis (1918): Bibliografia Chilena precedida de un bosquejo histórico sobre los primeros años de la prensa en el país, 1812-1817, Tomo II. Santiago de Chile, Imprenta Barcelona.

Myers, Jorge (2004): "Identidades porteñas. El discurso ilustrado en torno a la nación y el rol de la prensa: El Argos de Buenos Aires, 1821-1825", en Alonso, Paula (compiladora): Construcciones impresas. Panfletos, diarios y revistas en la formación de los estados nacionales en América Latina, 1820-1920. Buenos Aires, Fondo Cultura Económica.

Palti, Elías (2004): "Los diarios y el sistema político mexicano en tiempos de la República Restaurada (1867-1876)", en Paula Alonso (compiladora): Construcciones impresas. Panfletos, diarios y revistas en la formación de los estados nacionales en América Latina, 1820-1920. Buenos Aires, Fondo Cultura Económica.

Santa Cruz Achurra, Eduardo (2010): La prensa chilena en el siglo XIX. Patricios, letrados, burgueses y plebeyos. Santiago de Chile, Editorial Universitaria.

Santana, Francisco (1938): "Ensayo bio-bibliográfico sobre Camilo Henríquez y notas biográficas", en Atenea, 154, 92-118. Concepción, Chile, Universidad de Concepción.

Silva Castro, Raúl (1958): Prensa y Periodismo en Chile. Santiago de Chile, Ediciones Universidad de Chile.

Téllez Yáñez, Raúl (1945): Fray Camilo Henríquez. El patriota. Santiago de Chile, Imprenta y Litografía Stanley.

Weill, Georges (1974): El periódico. Orígenes, evolución y función de la prensa periódica. México, Editorial Limusa.

Eduardo Santa Cruz Achurra es periodista y licenciado en Ciencias Sociales. Es Profesor Titular del Instituto de Comunicación e Imagen, Universidad de Chile. 